\title{
Inulin and oligofructose in the dietary fibre concept
}

\author{
C. Cherbut* \\ Human Nutrition and Gut Function Department, INRA, BP 71627, 44316 Nantes cedex 03, France
}

\begin{abstract}
Dietary fibre consists of remnants of edible plant cell polysaccharides and associated substances resistant to hydrolysis by human alimentary enzymes, which may benefit health through a wide range of physiological effects. Inulin and oligofructose are storage carbohydrates found in a number of vegetables, fruits and whole grains. They resist digestion and absorption in the stomach and small intestine of humans, as shown by their almost full recovery at the end of the ileum of healthy or ileostomised volunteers. Inulin and oligofructose thus enter into the large intestine where they are available to fermentation, as demonstrated by increased breath hydrogen. Fermentation of both substrates is complete and no residue is found in human stools. Inulin and oligofructose improve laxation. Their bulking capacity comprised between 1.2 and $2 \cdot 1 \mathrm{~g}$ of stool per $\mathrm{g}$ of ingested substrate, results mainly from increases in microbial biomass in the colon. As water content of bacterial cells is high, stools are softer and easier to expulse. Stool frequency is thus increased, particularly in slightly constipated individuals. In addition, likely due to their fermentation properties, inulin and oligofructose also affect the intestinal epithelium (trophicity, mucin expression, etc.), that may strengthen mucosal protection and reduce the risk of gastrointestinal diseases. In summary, inulin and oligofructose are plant carbohydrates, resistant to digestion in the human small intestine and fermented by colonic bacteria. They exert several intestinal physiological effects contributing to maintenance of health. Therefore, inulin and oligofructose fit well within the current concept of dietary fibre.
\end{abstract}

Dietary fibre: Gastrointestinal functions: Stool bulking: Fermentation

\section{Introduction}

Since the original description of dietary fibre by Trowel (1974), the definition has been extensively debated. Nevertheless consensus has been progressively established to consider that dietary fibre consists of remnants of edible plant cell polysaccharides and associated substances resistant to hydrolysis by human alimentary enzymes. Very recently two new definitions have been proposed in the US by the American Association of Cereal Chemists (2001) and the Food and Nutrition Board of the Institute of Medicine of the National Academy (2001), respectively. Both definitions underline resistance to digestion and absorption in the human small intestine as being the key characteristic of dietary fibre. The AACC definition also identifies fermentation (partial or total) in the large bowel as an essential part of dietary fibre metabolism. Furthermore it clearly includes oligosaccharides as being part of the definition and it exemplifies some of the beneficial physiological effects that might be associated with dietary fibre consumption (American Association of Cereal Chemists, 2001). The definition proposed by the Food and
Nutrition Board (2001) simply refers to nondigestible carbohydrates but it proposes to distinguish between 'dietary fibre', 'added fibre' and 'total fibre' for labeling purposes.

Under the entity 'dietary fibre', a great variety of food components can be regrouped, mainly cell wall fractions as well as some storage carbohydrates. Because they are not hydrolysed and absorbed in the stomach and small intestine, these compounds reach the large intestine where they can be partially or completely fermented by the resident microflora. Their energy value is consequently lower than that of nutrients absorbed in the small intestine. During their passage through the upper intestine, they may influence the digestion process thus metabolic responses, while their fermentation in the large intestine affects transit and stool output as well as integrity of the mucosal barrier. These physiological effects are the basis for associating dietary fibre intake with reduced risk of chronic diseases such as cardiovascular disease and colorectal cancer. This review will consider whether inulin and oligofructose meet the requirements of the dietary fibre definition.

Abbreviations: OF, oligofructose; SCFA, short-chain fatty acids.

Note: For the definition of the terms inulin and oligofructose please refer to the introductory paper (p. S139) and its footnote.

* Corresponding author: Dr C. Cherbut, fax +33 2406750 12, email cherbut @ nantes.inra.fr 


\section{Inulin and oligofructose as dietary fibre}

\section{Inulin and oligofructose resist digestion in the small intestine}

D-Fructofuranosyl $\beta(1-2)$ links constitute the majority of glycosidic bonds in the inulin and oligofructose molecules. No enzyme able to split this glycosidic linkage is secreted by salivary glands and pancreas or is expressed in the gastric and small intestinal epithelium brush border in mammalians. Inulin and oligofructose thus resist hydrolysis in the human upper intestine. In patients with a conventional ileostomy, mean excretion of inulin and oligofructose at the end of the ileum was about $90 \%$ of the ingested dose (Ellegärd et al. 1997). Accordingly, in healthy volunteers, distal ileal output of oligofructose (from sucrose), determined by intestinal aspiration after a single meal containing $20 \mathrm{~g}$ oligofructose, was $89 \pm 8.3 \%$. Moreover, analysis of the constituent oligosaccharides in the ileal contents showed that most unabsorbed oligofructose was in an intact unhydrolysed form. Approximately $1 \%$ of the oligofructose (from sucrose) that disappear from the small intestine was recovered in urine (Molis et al. 1996). These results indicate that about $9 \%$ of inulin and oligofructose disappear from the small intestine in humans. Beside the errors due to the methods of recovery and analysis, it may be postulated that slight hydrolysis of ingested inulin or oligofructose occurs in the terminal ileum, where a low level of fermentation may physiologically take place.

\section{Inulin and oligofructose are fermented in the large intestine}

Inulin and oligofructose, not hydrolysed in the upper gastro-intestinal tract, are not recovered in the stools (Molis et al. 1996; Alles et al. 1996; Castiglia-Delavaud et al. 1998), indicating that they are completely fermented in the colon. Fermentation of carbohydrates by colonic microflora is an anaerobic process producing gas $\left(\mathrm{CO}_{2}\right.$, $\mathrm{H}_{2}, \mathrm{CH}_{4}$ ) and organic acids, among which lactic acid and short-chain fatty acids (SCFA) are found in colonic contents. Gases are utilised by bacteria, or absorbed then excreted in breath, or excreted in stools. Lactic acid accumulates or is further metabolised into SCFA (Macfarlane \& Cummings, 1991; Höve \& Mortensen, 1995). The major part of SCFA are absorbed and only a small, unrepresentative fraction is found in stools. Bacteria being provided with energy, they proliferate. This biomass is subsequently excreted in stools.

Inulin and oligofructose markedly enhance colonic fermentation. Their consumption increases breath hydrogen excretion in humans (Alles et al. 1996; Brighenti et al. 1999). When incubated in vitro with human faecal flora, they produce SCFA (Wang \& Gibson, 1993). This effect has been also demonstrated in rats harbouring a human faecal flora. In these animals fed a $10 \%$ fibre diet, caecal concentration of total SCFA was higher with inulin than with fibres from cereals (wheat and oat bran) or vegetables (carrot and pea). Furthermore, fermentation of inulin promoted butyrate production which molar ratio increased to $27 \%$ with inulin as compared to about $10 \%$ with the other fibres (Roland et al. 1995). A similar butyrogenic effect was reported with oligofructose in rats (Campbell et al. 1997; Le Blay et al. 1999). In humans, other authors did not find an increase in butyrate proportion (Gibson et al. 1995; Alles et al. 1996; Kleesen et al. 1997). However, butyrate concentration was determined in stools, which is considered of limited value in the evaluation of colonic fermentation (Nordgaard et al. 1995). In addition to butyrate, lactate production is also enhanced by inulin and oligofructose (Fig. 1). Increased lactate concentrations has been found in colonic and faecal contents of rats fed oligofructose from sucrose (Le Blay et al. 1999) as well as in stools of humans consuming inulin-containing breakfast cereals (Brighenti et al. 1999).

\section{Inulin and oligofructose are less energetic than starch and sucrose}

As inulin and oligofructose are not available in the small intestine but fermented in the colon, their energy value depends on their fermentability, energy lost as microbial biomass, $\mathrm{H}_{2}$ and $\mathrm{CH}_{4}$ and fermentation heat, and efficiency of SCFA and lactate utilisation (Livesey, 1992). Calculations from predictive theoretical equations have proposed that energy value of oligofructose ranges between 4.6 and
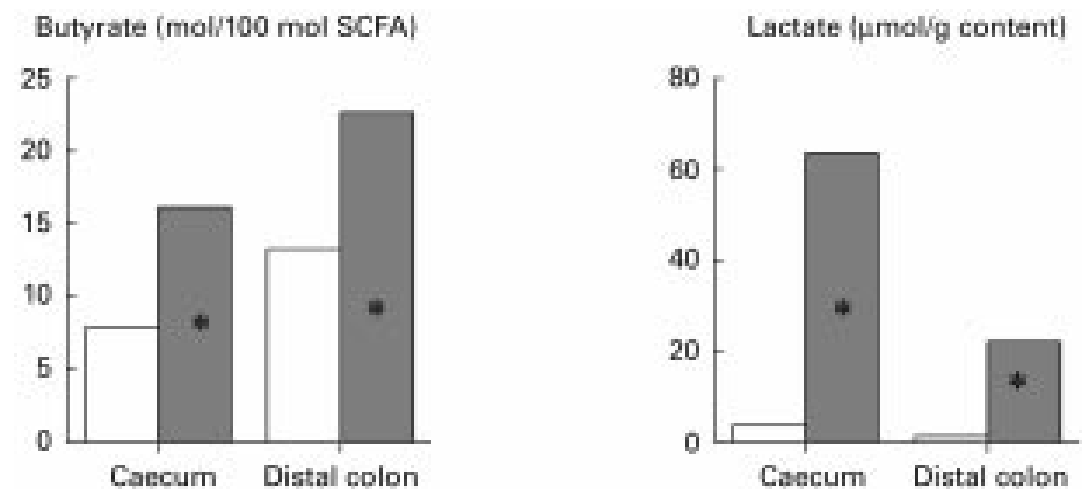

Fig. 1. Molar ratio of butyrate and concentration of lactate in caecocolonic contents of rats fed oligofructose (from sucrose) $(\mathrm{OF}+)$ or not (OF - ) for 2 weeks. cantly different from $\square, P<0.05$. From Le Blay et al. 1999. 
$9.5 \mathrm{~kJ} / \mathrm{g}$ (Roberfroid et al. 1993). Direct measurement of the metabolisable energy content of inulin, by wholebody indirect calorimetry, found a value averaging $12 \mathrm{~kJ} / \mathrm{g}$ in humans (Castiglia-Delavaud et al. 1998). All these data show that the energy value of inulin and oligofructose is lower than that of digestible carbohydrate $(17 \mathrm{~kJ} / \mathrm{g})$. Moreover, these substrates will contribute to less than $1-$ $3 \%$ of the total daily energy intake, which is negligible. For labelling purposes, their energy value could be set at $8 \mathrm{~kJ} / \mathrm{g}$ as recommended by the joint FAO/WHO expert consultation on carbohydrates (1998).

\section{Inulin and oligofructose increase stool output}

Dietary fibre can improve laxation by several ways. It can increase stool weight. The most important factor for a large effect on stool output is simply for the fibre to appear in stools. The contribution of bacterial cells to faecal mass should not be forgotten, as the water content of bacteria is high. The increase in faecal water content changes the consistency and plasticity of stool, easing excretion and increasing stool frequency. Certain dietary fibres can also stimulate large intestinal motility and reduce colonic transit time. However, inulin and oligofructose do not appear to exert such an effect.

The stool bulking indexes of inulin (about $2 \mathrm{~g}$ of stool increase per $\mathrm{g}$ of ingested substrate) and oligofructose $(1.2-1.5 \mathrm{~g} / \mathrm{g})$ are close to that of other soluble, fermentable fibres, such as pectins $(1.3 \mathrm{~g} / \mathrm{g})$ or guar gum $(1.5 \mathrm{~g} / \mathrm{g})$. The higher stool weight recorded in humans consuming inulin and oligofructose (Gibson et al. 1995) was probably due to an increase in the faecal bacterial mass, as both substrates are completely fermented (Fig. 2). As expected, the effect on stool output depends on the dose and on the amount of other fibres in the diet (Brighenti et al. 1999;

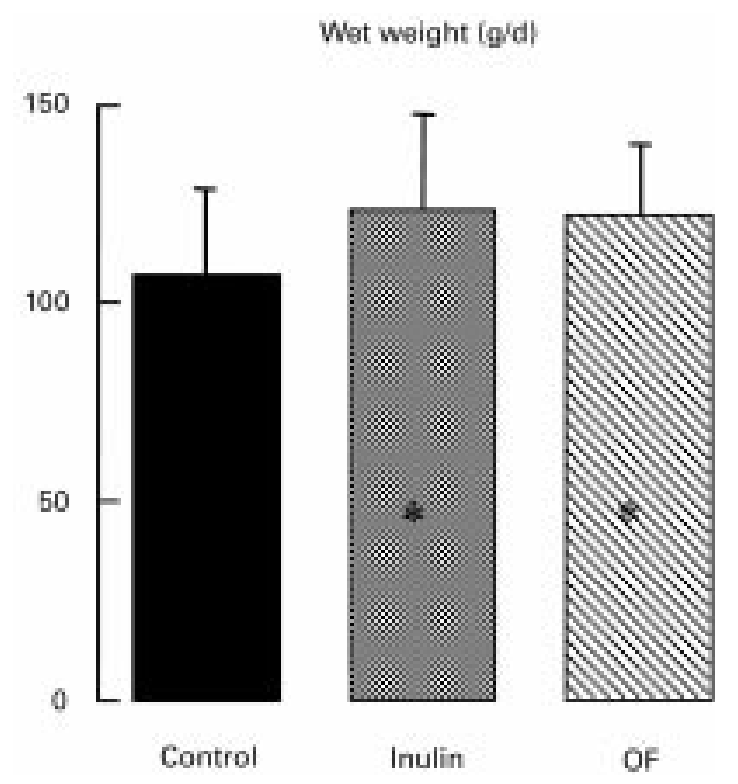

Fig. 2. Wet weight of stools $(\mathrm{g} / \mathrm{d})$ in healthy subjects who consumed $15 \mathrm{~g} / \mathrm{d}$ of sucrose $(\square)$, or inulin $(\square)$, or oligofructose $(\mathbb{\nabla})$ for 2 weeks. *Inulin or OF are significantly different from control, $P<0.05$. From Gibson et al. 1995. van Dokkum et al. 1999). Nevertheless, inulin and oligofructose intake has constantly increased faecal water content (Gibson et al. 1995; Kleessen et al. 1997; CastigliaDelavaud et al. 1998; Den Hond et al. 2000; van Dokkum et al. 1999). In addition, inulin has been shown to stimulate bowel movements and to increase stool frequency, particularly in slightly constipated subjects (Kleessen et al. 1997; Den Hond et al. 2000).

\section{Inulin and oligofructose could modulate several aspects of intestinal epithelium integrity}

It is largely accepted that SCFA, especially butyrate, play an essential role in maintenance of colonic mucosa integrity, by acting on metabolism, proliferation and differentiation of the different epithelial cell types (Blottière et al. 1999). On the other hand, it is possible that certain bacteria directly influence epithelial cell functioning as it has been shown for some lactobacilli (Mack et al. 1999). Inulin and oligofructose are prebiotic and could produce significant amount of butyrate. They may therefore modulate the intestinal barrier function. The hypothesis has been scarcely tested and no evidence exists in humans at this time. However, supplementation with oligofructose increased mucosal crypt height and leading edge, and epithelial cell density and proliferation in the large intestine of neonatal pigs, preventing thereby colonic epithelial atrophy observed in piglets fed an elemental diet (Howard et al. 1995). Caecocolonic mucosa contained higher amounts of sulphomucins and lower amounts of sialomucins in rats (heteroxenic rats harbouring a human faecal flora) fed an inulin diet as compared to sucrose diet (Fontaine et al. 1996). The same distribution was found in contents. This effect could be interesting to consider since sulphomucins are in general associated to a higher level of protection, and their proportion is decreased in several intestinal diseases such as inflammation or certain forms of cancer. These effects may explain the stimulation of mucosal repair in

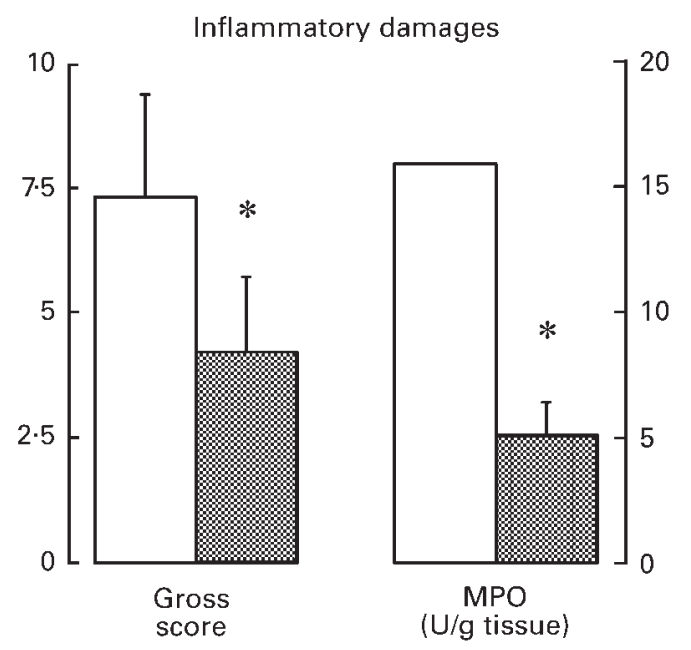

Fig. 3. Reduction of intestinal mucosal damages, assessed by macroscopic scoring (gross score) and myeloperoxidase activity (MPO), by synthetic oligofructose (from sucrose) in rats with a colitis induced by trinitrobenzene sulphonic acid. OF $(\square)$ is significantly different from control $(\square), P<0.05$. 
colitis rats given oligofructose (Fig. 3; unpublished data). In these rats, treatment with oligofructose (from sucrose) $1 \mathrm{~g} /$ day inhibited the anorexia and weight loss associated with the onset of inflammation and reduced the extent of epithelial damage assessed by macroscopic examination and measurement of myeloperoxidase activity (specific enzyme marker of polymorphonuclear neutrophil primary granules).

\section{Conclusion}

Inulin and oligofructose are plant carbohydrates resisting digestion in the upper gastrointestinal tract and fermented in the colon. By increasing faecal biomass and water content of stools, they improve bowel habits. Likely due to their specific fermentative properties, they affect several functions involved in colonic mucosal protection and repair, which may contribute to reduce the risk of intestinal diseases. For all these reasons, inulin and oligofructose are undoubtedly part of the dietary fibre complex. In addition, they do have characteristic features different from those of other fibres. Therefore, they may contribute in a significant way to a well-balanced diet by increasing the fibre content, by improving the diversity of the fibre sources and by their specific effects on several physiological functions.

\section{References}

Alles MS, Hautvast JGA, Nagengast FM, Hartemink R, Van Laere KMJ \& Jansen JBM (1996) Fate of fructo-oligosaccharides in the human intestine. British Journal of Nutrition 76, 211-221.

American Association of Cereal Chemists (2001) The definition of dietary fiber. Report of the Dietary fiber definition committee to the Board of Directors, DF DEF 1/10/2001.

Blottière HM, Champ M, Hoebler C, Michel C \& Cherbut C (1999) Les acides gras à chaîne courte: de la production aux effets physiologiques gastro-intestinaux (Production and digestive effects of short chain fatty acids). Sciences des Aliments 19, 269-290.

Brighenti F, Casiraghi MC, Canzi E \& Ferrari A (1999) Effect of consumption of a ready-to-eat breakfast cereal containing inulin on the intestinal milieu and blood lipids in healthy male volunteers. European Journal of Clinical Nutrition 53, $726-733$.

Campbell JM, Fahey GC \& Bryan WW (1997) Selected indigestible oligosaccharides affect large bowel mass, cecal and fecal short chain fatty acids, $\mathrm{pH}$ and microflora in rats. Journal of Nutrition 127, 130-136.

Castiglia-Delavaud C, Verdier E, Besle JM, Vernet J, Boirie Y, Beaufrère B, De Baynast R \& Vermorel M (1998) Net energy value of non-starch polysaccharide isolates (sugarbeet fibre and commercial inulin) and their impact on nutrient digestive utilization in healthy human subjects. British Journal of Nutrition 80, 343-352.

Den Hond E, Geypens B \& Ghoos Y (2000) Effect of high performance chicory inulin on constipation. Nutrition Research 20, $731-736$.

Ellegard L, Andersson H \& Bosaeus I (1997) Inulin and oligofructose do not influence the absorption of cholesterol, or the excretion of cholesterol, $\mathrm{Ca}, \mathrm{Mg}, \mathrm{Zn}, \mathrm{Fe}$, or bile acids but increases energy excretion in ileostomy subjects. European Journal of Clinical Nutrition 51, 1-5.
Fontaine N, Meslin JC, Lory S \& Andrieux C (1996) Intestinal mucin distribution in the germ-free rat and in the heteroxenic rat harbouring a human bacterial flora: effect of inulin in the diet. British Journal of Nutrition 75, 881-892.

Food and Agriculture Organization of the United Nations (1998) Carbohydrates in human nutrition. Report of a joint FAO/WHO expert consultation. No. 99. Rome: FAO.

Food and Nutrition Board, Institute of Medicine (2001) Dietary reference intakes: proposed definition of dietary fiber. National Academy Press Washington, DC, USA.

Gibson GR, Beatty E, Wang X \& Cummings JH (1995) Selective stimulation of bifidobacteria in the human colon by oligofructose and inulin. Gastroenterology 108, 975-982.

Höve H \& Mortensen PB (1995) Colonic lactate metabolism and D-lactic acidosis. Digestive Disease and Sciences 40, 320-330.

Howard MD, Gordon TD, Pace LW, Garleb KA \& Kerley MS (1995) Effects of dietary supplementation with fructo-oligosaccharides on colonic microbiota populations and epithelial cell proliferation in neonatal pigs. Journal of Pediatric Gastroenterology and Nutrition 21, 297-303.

Kleesen B, Sykura B, Zunft HJ \& Blaut M (1997) Effects of inulin and lactose on fecal microflora, microbial activity, and bowel habit in elderly constipated persons. American Journal of Clinical Nutrition 65, 1397-1402.

Le Blay G, Michel C, Blottière HM \& Cherbut C (1999) Prolonged intake of fructo-oligosaccharides induces a short-term elevation of lactic acid-producing bacteria and a persistent increase in cecal butyrate in rats. Journal of Nutrition 129, $2231-2235$.

Livesey G (1992) The energy values of dietary fibre and sugar alcohols for man. Nutrition Research Reviews 5, 61-84.

Macfarlane GT \& Cummings JH (1991) The colonic flora, fermentation, and large bowel digestive function. In The Large Intestine: Physiology, Pathophysiology, and Disease, pp. 51-92 [SF Phillips, JH Pemberton and RG Shorter, editors]. New York: Raven Press Ltd..

Mack DR, Michail S, Wei S, McDougall L \& Hollingsworth MA (1999) Probiotics inhibit enteropathogenic E. coli in vitro by inducing intestinal mucin gene expression. American Journal of Physiology 276, G941-950.

Molis C, Flourié B, Ouarne F, Gailing MF, Lartigue S, Guibert A, Bornet F \& Galmiche JP (1996) Digestion, excretion, and energy value of fructooligosaccharides in healthy humans. American Journal of Clinical Nutrition 64, 324-328.

Nordgaard I, Hansen BS \& Mortensen PB (1995) Colonic fermentation of complex carbohydrates in short-bowel patients. No association with hydrogen excretion and fecal and plasma short-chain fatty acids. Scandinavian Journal of Gastroenterology 30, 897-904.

Roberfroid M, Gibson GR \& Delzenne N (1993) The biochemistry of oligofructose, a nondigestible fiber: an approach to calculate its caloric value. Nutrition Reviews 51, 137-146.

Roland N, Nugon-Baudon L, Andrieux C \& Szylit O (1995) Comparative study of the fermentative characteristics of inulin and different types of fibre in rats inoculated with a human whole faecal flora. British Journal of Nutrition 74, 239-249.

Trowel H (1974) Definition of fiber. Lancet 1, 503.

Van Dokkum W, Wezendonk B, Srikumar TS \& van den Heuvel EGHM (1999) Effect of nondigestible oligosaccharides on large-bowel functions, blood lipid concentrations and glucose absorption in young healthy male subjects. European Journal of Clinical Nutrition 53, 1-7.

Wang X \& Gibson GR (1993) Effects of the in vitro fermentation of oligofructose and inulin by bacteria growing in the human large intestine. Journal of Applied Bacteriology 75, $373-380$. 